*Blinded Manuscript: Resubmission (WITHOUT Author Details)

\title{
Being Knowledge, Power and Profession Subordinates: Students' Perceptions of Twitter for Learning
}

\begin{abstract}
Further conceptualisations are needed on students' actual engagement with and perceptions of Twitter for learning. A United Kingdom-based study with a cohort of Year1 Physiotherapy students is reported, identifying: 1) the frequency of student self-initiated use of social media (SM) and Twitter, and 2) perceptions of Twitter and factors that would discourage or facilitate students to use Twitter for learning. An optional Twitter learning activity was created for one module, but students opted not to contribute. Forty-three students were surveyed, and two focus groups held with 12 students. Results suggest the perceived role of Twitter to reinforce student knowledge and power subordination as opposed to leading users in disciplines or professions and act as a career/business tool. These are discussed and problematised, suggesting a 'digital information activation' (Dig-Info-Act) pedagogy with SM in HE, an orientation of acting upon SM information towards relevant change.
\end{abstract}


Keywords: Twitter, social media, students’ perceptions, Higher Education (HE), learning, critical engagement

Highlights: Student-reported uses of SM and Twitter for 'learning' is low; There were two main obstacles to contributing to Twitter: student use of technology for learning and students' perceptions of the Twitter platform; Students perceived Twitter in two dominant manners: as an employability tool and an SM tool for and led by celebrity-like, knowledgeable others, the Academic and Professional Twitterati (APT); Students adopted a 'subordinate' position to the APT; 'Twitter for learning' obstacles and enablers are here presented at a micro level and further development of a Digital Information Activation (Dig-Info-Act) Pedagogy is proposed, towards critical education and social change, as a way to pedagogically challenge student Twitter and SM subordination.

\section{Introduction}

\subsection{Twitter as a part of social media: general impact and HE learning potential}

The proposition that social media (SM) have penetrated so deeply into our lives is not a hype or fad. Social media engagement statistics for 2016 show a staggering 1.71 billion monthly active users of Facebook and 313 million Twitter accounts worldwide (Statista, 2016). However, it is also fair to say that these figures are unevenly spread across the world. A significant bulk of users is located in the United States (U.S.); Pew Research Centre reports that Facebook is the largest social networking site in the U.S., reaching $67 \%$ of U.S. adults. Two-thirds of Facebook users seek news there, amounting to $44 \%$ of the general population (Gottfried \& Shearer, 2016). A much smaller percentage of the U.S. population uses Twitter $-16 \%$, but more users turn to Twitter for news than to Facebook, relative to the number of registered users $-9 \%$ of the general U.S. population. The above-mentioned statistics 
illustrate Twitter as the media not yet fully embraced like its older relative Facebook (Facebook was founded in 2002 and Twitter in 2006). The article is not going to provide any further historical and statistical data on social media and Twitter here since others have done this (e.g. Roblyer, McDaniel, Webb, Herman, \& Witty, 2010). It is highlighted rather that users have surpassed any original purpose quickly (e.g. status updates to say what they are doing right now), and appropriated social media to serve many other purposes, that are also social but more focused and change-oriented, for example activism (Earl, McKee Hurwitz, Mejia Mesinas, Tolan, \& Arlotti, 2013).

When it comes to HE potential for SM, many studies have looked into SM and tertiary educational experiences (e.g. Ebner, Lienhardt, Rohs, \& Meyer, 2010; Kanjanapongpaisal, Rogers, \& Bryan, 2012; Fox \& Varadarajan, 2011). However, there are still uncertainties in terms of exactly what kind of contribution to learning - however this learning may be defined - social media can claim. For example, it is argued that students rarely use social media to support their studies (Forkosh-Baruch \& Hershkovitz, 2012). Yet, it seems that Facebook may enhance better psychosocial outcomes (Ellison, Steinfield, \& Lampe, 2011) whereas Twitter may support better academic outcomes (Junco, Heiberger, \& Loken, 2011). Furthermore, students are reported to resist the idea of "mixing" social media with learning, wanting to preserve boundaries between "academic" and "social" (Rinaldo, Tapp, \& Laverie, 2011).

There is no consensus on the effect of SM in education: this "effect" is approached from various vantage points in HE, spanning across disciplines, methods and aims. Some commentators argue that the "great" SM potential in education might fail to be adopted “to have any real impact" in HE (Roblyer et al., 2010, p. 138; Forkosh-Baruch \& Hershkovitz, 2012). In addition, Greenhow and Lewin (2016, p.7) state that "only a small 
proportion of young people are actually using social media in sophisticated ways that educators might value (Eynon \& Malmberg, 2011; Ito et al., 2008)”. Although there are useful publications that offer advice on what works and what steps to undertake for successful SM and technology integration in HE (e.g. dating back to Chickering \& Ehrmann, 1996), related pedagogies have not become as widely spread as might have been expected in HE. SM applications and interventions are still happening mostly as individual projects rather than as an adopted institutional and departmental learning and teaching strategy. However, research on SM and its educational role has been thriving. As Selwyn and Stirling (2016, p.3) emphasise, "(f)rom the establishment of Facebook groups in university math courses to the use of Twitter as an in-class 'back-channel', any academic journal interested in educational technology and educational media is now replete with discussions of the educational potential of social media". The authors (Selwyn \& Stirling, 2016, p.3) also contend that "there continues to be a tendency amongst education studies of social media to look primarily for good news, 'best practice' and examples of 'what works' (see Piotrowski, 2015)". More studies are therefore needed to further understand and critically conceptualise the actual use of social media and technology in HE pedagogy (Selwyn and Stirling, 2016), its nature and how students perceive it (Henderson, Selwyn, Finger, \& Aston, 2015). This is beneficial for creating a better-rounded picture of SM-for-learning in HE, adding to the existing body of knowledge. There is far less research on Twitter for HE learning than on Facebook, and the article turns to this medium.

\subsection{Twitter in HE learning: a brief landscape}

There has not been a wide adoption of Twitter as a learning technology among students (Evans, 2013; Rinaldo et al., 2011). Competing data do exist, however, on findings about 
the effect Twitter may have on student learning (Knowlton \& Nygard, 2016), again, depending on the angle taken on "learning". Some suggest that using Twitter can increase overall student engagement with regard to both extracurricular and curricular activities (Evans, 2013; Junco et al., 2011). In addition, it has been highlighted that Twitter can be a useful pedagogical tool in HE (Blessing \& Blessing, 2012; Rinaldo et al., 2011). To illustrate this pedagogical use, the tutor in one study, a Twitter novice, created a subjectrelated Twitter account and advised students to follow the account (Rinaldo et al., 2011). Students emphasised the value of Twitter as a "career preparation" tool, whatever connection to learning would be concluded. The authors also noted some 'negative' students' attitudes such as: resistance to use Twitter due to the issues of credibility (student as incompetent); privacy (no mixing of "social" and "academic" life, no mixing with the tutor in social media) and the lack of knowledge on what it is and why to use it; the struggle with demystifying Twitter symbols; and understanding what it has that Facebook does not (Rinaldo et al., 2011).

To problematise the use of Twitter for learning further, Henderson et al. (2015) reported that although nearly half of the students $(n=1658)$ use Twitter for academic study, only $14.5 \%$ find it "useful" of "very useful". In a similarly critical manner, it has been argued that Twitter can bring no considerable difference in levels of student-reported learning engagement (Welch \& Bonan-White, 2012). On the other hand, positive outcomes of Twitter use in HE learning are reported in various ways and in relation to particular learning contexts, for example: collaboration, information sharing and community building for distance learners who followed a particular hashtag (Ricoy \& Feliz, 2016), improved student sense of community (Ross, Banow \& Yu, 2015), augmented content, such as linking course topics with current news and activities for use outside and inside large classes, albeit not for active discussion and feedback (Jacquemin, Smelser, \& 
Bernot, 2014). In all the above cases that reported positive Twitter influence on student learning, the tutor/instructor's role is noted, signaling the necessity of highly supportive, interventionist roles of the tutor (e.g. the tutor reacts when there is little or no tweeting, when there are problems, technical or otherwise). But, what happens if students are given enough information and support in the beginning but need to decide for themselves whether to contribute or not to their module hashtag/\# (\# andtheme/topic (here the module's acronym) is inserted in the Twitter search tab and shows a thread of tweets that included that \# and theme/topic)? What do they report as motivating or demotivating for their contribution? These questions inspired the study design, alongside the need to further develop an understanding of what counts as 'useful' to students, how they perceive Twitter and what that means for pedagogy with Twitter in HE, which are the overarching aims of this study. The authors were also interested to explore whether students expressed any requirements for tutor intervention and "embedding" Twitter activity in the course. In the case of this study, students were encouraged to contribute to Twitter outside the lecture theatre after an initial introduction and available support, with a possibility to discuss tweets at the beginning of lectures, but the decision on contribution was entirely in the hands of the students, with minimal tutor/teacher interference.

\subsection{The study aims}

This research was focused on four inter-related research questions (RQs):

RQ1. What is the frequency of student-reported use of the internet and related social media and technology, in general and in relation to learning? 
RQ2. How do students perceive Twitter for learning (learning = related to the created Twitter hashtag to support particular module learning) and the nature of the Twitter platform?

RQ3. What are student-reported obstacles and enablers for students' use of Twitter for learning?

RQ4. What implications for the practical and critical use of SM and Twitter in HE pedagogy can be concluded?

\section{Methodology}

\subsection{Study context}

The study setting was a Year 1 compulsory module which formed part of an undergraduate degree programme (Bachelor of Science in Physiotherapy) at a UK HE institute. The module was entitled 'Evidence Based Practice (EBP) 2'. A module-specific hashtag (\#EBP2) was created. In addition to the regular lectures and seminars, discussions (questions/comments/sharing of information and links) under the hashtag were encouraged for a period of eight weeks. The project was introduced to a Year One physiotherapy cohort of 43 students by two researchers, one of whom was a part of the teaching team on the module. To avoid any conflict of interest and participation pressure, it was particularly stressed that level of engagement would not affect students' final results. 


\subsection{Twitter activity}

Following each weekly lecture, a question related to that lecture was tweeted for students to respond to. This question was tweeted by the contributing teacher-researcher. The students were encouraged to tweet at the end of the lecture few times. The teacher observed any subsequent Twitter activity and would contribute to conversations linked to \#EBP. The students were advised to follow the teacher who tweeted questions, and to follow each other. There was no further specific "modelling" of Twitter use by the teaching staff, in line with departmental culture, policy and standardised pedagogical practice for modules that are taught by a number of tutors. Beside initial in-lecture instruction and examples of how Twitter can benefit student learning, a detailed document on how to use Twitter was emailed to students and comprehensive support offered, including face-to-face meetings which no student requested. To reiterate, bound by the rules of standardized instruction, the study relied solely on:

- Students' engagement on their own accord.

- Lecturers encouraging students to tweet or reminding students about it from time to time; this happened a few times.

The main difference between this intervention and other Twitter interventions found in the literature is our focus on maximum initial instruction but minimal tutor interference and instruction during the study, unless students asked questions. Furthermore, the module hashtag could be accessed by a wide range of physiotherapy practitioners and academics, the followers of the tutor-researcher. Those practitioners were actively contributing to the hashtag, reacting to the module questions the tutor tweeted. It was 
perceived that this big pool of experts would inspire students to join, ask questions or comment, but it may have been one of the factors that stifled their contribution.

\subsection{Participants}

The study received research ethics approval by the Faculty of Medicine and Health Sciences Ethics Committee at the university where the study took place. In the Year One cohort, there were 43 students. The average age of the cohort was 21 years with 34 of them aged between 18 and 20 years, and nine over 21 years. There were 30 female and 13 male students. Twenty-seven students did not own a tablet device, and six did not own a smartphone.

\subsection{Questionnaire}

Before the creation of the hashtag and its implementation, the teacher-researcher asked all the Year 1 students taking the module $(n=43)$ to fill in a questionnaire related to their use of social media and portable devices, distinguishing between use for personal reasons (e.g. entertainment) and for learning purposes (e.g. learning something related to your module, course or general interest within the profession). The questionnaire gathered evidence to address RQ1 and consisted of three parts: Part 1: Demographic information (2 items on gender and age); Part 2: Technology use with six items; and Part 3: Academic engagement with three items. The results of Part 2 are reported here, containing items such as "Please indicate how often you use the following Web 2.0 platforms for personal 
purposes (i.e. chatting and communicating with friends/family, organizing social events, posting updates about your day-to-day life, following friends/family, reading updates about favorite celebrities/writers/businesses/sports teams, etc.)", followed by a table with a list of platforms such as Facebook and Twitter with six-scale frequency response options from "Daily" to "Never" (see the relevant results we report in Tables 2 and 3 in section 3.1). Quantitative data from students' questionnaires were generated and tables created based on the survey responses.

\subsection{Focus group}

Following the end of the eight-week study period, two focus groups were conducted with 12 student volunteers (six male, six female), all in their early twenties. Focus group participants were recruited via an email, seeking volunteers, sent to students' university emails, in addition to information about it given out at the end of the class and breaks. The targeted students attended the EBP module. All volunteers were active users of smartphone technology. The purpose of the focus groups was to explore students' perceptions of Twitter for learning and reactions to the Twitter intervention hashtag that was intended for their active engagement (relating to RQ2). In particular, the authors were interested to uncover the reasons behind non-contribution, that is, student-reported obstacles and enablers for the use of Twitter for learning (relating to RQ3). The focus groups followed the following questioning format: 
Can you give us a brief account of how you use social media generally?

Do you use SM and Twitter to support your learning related to your University course?

\section{Exploration questions (30 minutes)}

OK, so you don't use Twitter in learning, can you comment on why not? What do you think would motivate you to engage in using Twitter for learning?

So, in relation to the EBP Twitter stream, why did you not feel motivated to engage?

\section{Exit question}

Is there anything else you would like to comment on about either Twitter in learning in general, or about the EBP \#?

Conversations were audio recorded. Each student was given a pseudonym name to protect their identity. Audio recordings were transcribed verbatim.

\subsection{Focus group content analysis}

A focused approach using thematic analysis (Vaismoradi et al., 2013) was adopted. The following coding procedure in line with this approach (Vaismoradi et al., 2013, p. 402) was applied by the authors:

- Familiarising with the data:

Transcribing data, reading and rereading the data, noting down initial ideas. 
- Generating initial codes:

Coding interesting features of the data systematically across the entire data set, collating data relevant to each code.

- Searching for themes:

Collating codes into potential themes, gathering all data relevant to each potential theme.

- Reviewing themes:

Checking if the themes worked in relation to the coded extracts and the entire data set, generating a thematic map.

- Defining and naming themes:

Ongoing analysis for refining the specifics of each theme and the overall story that the analysis told, generating clear definitions and names for each theme.

- Producing the report:

The final opportunity for analysis. Selection of vivid, compelling extract examples, final analysis of selected extracts, relating back to the research questions and literature, producing a report of the analysis.

\subsection{Study limitations}


The study is limited in its scope, since it builds on the data from a case study, provided by a small group of students from a single module at one university. However, the sample is representative of Year 1 students on one entire programme. Furthermore, the students were encouraged to speak on behalf of the group and friends, the "student population", not just reporting their personal opinions. The students were frequently asked during the focus group: "Do you think that this is a general feeling or attitude among students in general and your peers?" The aim was to uncover students' perceptions on their peers' general use of technology, not any particular observation of it, which may or may not have been accurate. Therefore, students were asked what they thought their peers' uses of technology (mostly Twitter) was, based on their own experience and peer interaction.

\section{Results and Discussion}

At the end of the Twitter hashtag life planned for this project (eight weeks), there was no student contribution with tweets (other than one tweet). This might have been for a variety of reasons, for example, other class requirements taking over. Furthermore, students may have passively participated as observers of the hashtag and gained useful insights. However, in this article, the focus is on understanding why they did not actively contribute with tweets and what would motivate them to do so. The hashtag developed a life of its own and many physiotherapy professionals and even a few students from other universities were actively tweeting, possibly due to the tutor's big Twitter networks. The content of tweets contained a large number of critical questions and commentaries.

Two major themes were identified in the analysis of student questionnaires and the focus group transcripts with regard to our research questions. The analysis characterised Twitter 
obstacles to student contribution as "technology use obstacles" and "obstacles related to the perception of Twitter", the latter organised around the concepts of "career/profession" and "celebrification". A list of "enablers" was identified, that is, what most students thought and/or agreed would encourage them to use Twitter for learning.

\subsection{Technology use obstacles: selective use of social media and not for learning}

Questionnaire data show that six students out of 43 did not own a smartphone which signals that it cannot be presumed that all students would own a particular device, even if this has become a socio-cultural imperative for younger generations in most western societies. Furthermore, the majority of our respondents (approximately 63\% - 27 out of 43) did not own a tablet device. All these factors are important when considering using Twitter and any SM for learning, since Twitter is a particularly smartphone/tablet-friendly platform. SM requires constant smartphone connectivity (3G or 4G or "what G comes next" smartphone support). When planning and making sweeping claims on technology use and benefits for students' learning, one cannot overlook the question of "Benefits for whom?". The study took place in the UK, a country with 26.4 million smartphone users in 2014 according to Statista portal. The distribution of smartphone and tablet owners in other parts of the world may differ dramatically. Therefore, it is acknowledged that this study is about Twitter and SM for learning in a particular Western context.

Table 1 below shows that Facebook is still by far the most popular SM: almost all students (95\%) use it daily for personal interest and often for learning purposes, albeit $35 \%$ never do so (Table 2 ).

\begin{tabular}{|l|l|l|l|l|l|l|}
\hline & Daily & Once a & $\mathbf{2 - 3}$ & Every few weeks & Monthly or & Never \\
\hline
\end{tabular}




\begin{tabular}{|l|l|l|l|l|l|l|}
\hline Twitter & 12 & 3 & 4 & 0 & 1 & 23 \\
\hline Facebook & 41 & 0 & 1 & 0 & 0 & 1 \\
\hline Linked In & 0 & 0 & 0 & 1 & 0 & 42 \\
\hline
\end{tabular}

Table 1. Frequency of selected SM use for personal interest and networking purposes

$(\mathrm{N}=43)$

Twitter, on the other hand, was never used for personal interest and networking by $53 \%$ of the students, and the majority of students (72\%) never used it for learning purposes (Table 3), in line with the studies reported earlier (Evans, 2013; Rinaldo et al., 2011).

\begin{tabular}{|l|l|l|l|l|l|l|}
\hline & Daily & Once a & $\mathbf{2 - 3}$ /week & Every few & Monthly or & Never \\
\hline Twitter & 0 & 3 & 1 & 1 & 7 & 31 \\
\hline Facebook & 5 & 5 & 6 & 6 & 6 & 15 \\
\hline Linked In & 0 & 0 & 0 & 1 & 1 & 41 \\
\hline
\end{tabular}

Table 2. Frequency of selected SM use for learning purposes (e.g. subject/profession related; accessing academic resources and information) $(\mathrm{N}=43)$

\begin{tabular}{|l|l|l|l|l|l|l|}
\hline & Daily & Once & $\mathbf{2 - 3}$ & Every & Monthly & Never \\
& & a week & /week & few & or less & \\
\hline Texting & 43 & 0 & 0 & 0 & 0 & 0 \\
\hline E-mailing & 29 & 0 & 3 & 2 & 2 & 7 \\
\hline Social media & 33 & 0 & 3 & 0 & 0 & 7 \\
\hline access/interaction & & & & & & \\
\hline Enternet browsing & 31 & 0 & 6 & 0 & 0 & 6 \\
\hline
\end{tabular}




\begin{tabular}{|l|l|l|l|l|l|l|}
\hline $\begin{array}{l}\text { Study related } \\
\text { reading/browsing/performing }\end{array}$ & 5 & 4 & 4 & 3 & 5 & 22 \\
\hline
\end{tabular}

Table 3. Frequency of using mobile devices (phones/smartphones/tablets) for different purposes $(\mathrm{N}=43)$

In terms of the type of activities that students do with their mobile devices (Table 3), approximately half of the participants (51\%) reported never using their mobile phones for study-related tasks. Although the majority did use e-mail, text and use SM on a daily basis, $48 \%$ of all students reported not to use smartphones or tablets for study-related learning. These findings support the "big data" findings by Henderson et al. (2014) on student (non-)use of technology for learning. The question of where and how students make this studying/non- studying use and content demarcation remains. In spite of the growing research and arguments in favour of the application of mobile phones in HE for learning (Gikas \& Grant, 2013), such applications may still be rare. This may be so since those devices and SM have not become a part of teaching-learning methods. Therefore, first obstacles for using Twitter for learning are the ones related to established patterns and learning habits related to SM and mobile devices use, as well as to students' learning environment.

The most puzzling result (to us) was that 12 students used Twitter for personal reasons on a daily basis and three used it once a week for learning purposes but they still chose not to contribute. The reasons behind this non-contribution, reported by 12 students in two focus groups, are discussed below.

\subsection{Obstacles relating to the perception of Twitter}




\subsubsection{The "Business" of Twitter: Twitter as a career vehicle}

In line with Rinaldo et al. (2011), students prominently saw Twitter as a SM platform for boosting employability and career. The following extracts illustrate this view:

Tiffany: I found Twitter very useful for business because it's so simple to tweet stuff. I know people who use Twitter extensively for their business and they get loads of work out of it.

Olivia: And when you've got a specialism as well then you've got more of an interest, yeah.

Oscar: It's also about employability as well. I'm aware of some students who have their own personal account and they look almost professional...

Feeling the need to "economise" and "prioritise" what learning resources to use, students told us that Twitter had a status of "just one more SM" juxtaposed with Facebook that had already gained widespread use among students as a platform that can support their learning in some way. Students viewed Twitter as a career vehicle, and that was an obstacle to their engagement in Year 1 since they thought it was too early to think about the career.

If Twitter is viewed as an employability tool, this may mean that it is not viewed as related to the "curriculum" and hence it is not a learning tool: such a discrepancy in students' and tutors' perceptions between graduate "curriculum" and graduate “employability” has been noted (Speight, Lackovic \& Cooker, 2013). Students may prioritise tools and resources that get them a degree in line with the learning requirements (Molesworth, Nixon \& Scullion, 2009). The problem arising from the perception of 
Twitter as a "business tool" is not the characterisation of the tool as such. Perceiving Twitter as a "business tool" is not a new or bad idea. For example, Comm (2010) advises businesses "how to dominate your market one tweet at a time", Bulearca and Bulearca (2010) clearly call it a "business tool" whereas Loudon and Hall (2010) contemplate how the use of Twitter moves from trivial to business. The problem is that if educators see value in using Twitter for learning, then they may need to have strong and compelling arguments for doing so and support in practice students' understanding of such learning potential. Otherwise, Twitter only adds to the "employability" - "curriculum" division, where enhancing one's employability is positioned outside the curriculum, which is yet another debate that will not be opened further here. Instead, a question is raised whether students need to recognise another role of Twitter that they did not mention, the one of "new (digital) social movements" (Bennet, 2012) where people of common interests get together to engage in Twitter discussion and activism around multiple causes, as mentioned at the beginning of the article. Not all "activist" uses can lead to envisaged and desirable changes; but some have a solid potential for ameliorating issues of social and economic injustice (Bennet, 2012). It is not clear to what extent this type of understanding of social media is seen as needed in HE pedagogy. Most studies focus on classical learning outcomes and factors that support learning, as presented in the first part of our paper. Studies that look at students' engagement with Twitter towards social/community actions and change are scarce. Related publications on Twitter activism (such as Hands, 2011) target students of politics and media, whereas these issues concern all students as conscientious citizens and members of their communities and societies, not just a particular student group. Why is this understanding important?

There is much vagueness surrounding student engagement and participation in general (Ashwin \& McVitty, 2015). This study focuses on the commonly overlooked 
"engagement" with Twitter, the one of social media action towards learning and social change as contrasted to its "business" function. It stresses the lack of perceiving “activist”, "change indicting” (Hands, 2011) and inequalities-perpetuating (Selwyn \& Stirling, 2016) characters of Twitter as compared to its "business" one. In a nutshell, students saw Twitter as an "entertainment, news, business and career" tool, not as a tool for communication that can be critically analysed and related to social change. The main message they carried forward from their SM training sessions was the cautionary tale of social media disasters and dangers, which is of course beneficial for students to be fully aware of, but the issue arises when this is the dominant approach to SM that students adopt. There is a need to explore, conceptualise and theorise this issue further. Indeed, one rightly needs to be cautious of ideological and other "dangers" of SM activist engagement that, according to Schneider and Goto-Jones (2014), can reinforce “cyber utopia" considering well-developed surveillance and control mechanisms, and perhaps extreme views and behaviours. However, this article argues that SM issues such as social justice, change, evidence, ideology, power and discourse need to be a part of student learning with SM, either as a part of extra-curricular or preferably curricular SM information and sessions. When it comes to power, power relations are ingrained in societies and education is no exception. Students' resistance to participate due to "power" issues is tackled in the next section.

\subsubsection{The "Celebritification" of Twitter: knowledge and power tension}

Major obstacles to engagement and contribution expressed by all were around students' perceptions of Twitter as a platform for the more knowledgeable, experienced and powerful users of Twitter, the group here called Academic and Professional Twitterati (APT). The term “Twitterati” refers to keen or frequent users of Twitter. Students 
mentioned several times the people who were seen by them as leading figures on Twitter in relation to their discipline, using the constructs such as "top physios" or "crème de la crème". Indeed, Twitter communication seems to be strongly led by the apt, established practitioners, leading individuals or organisations and avid SM users in various professions. They often have a large pool of "followers", the users who follow their profiles and react/respond to their tweets. The number of novices actively tweeting (Year 1 students) is questionable; the ones who engage are probably technology savvy and SM enthusiasts. Such professional-novice positioning on Twitter that privileges someone's knowledge and status and hence power (Apple, 2013; Giroux, 1988) are embodied in the following students' statements - the boldened parts emphasise that:

John: It is also about the credibility of the person who is tweeting as well? Because you've got to be careful because you might have a person whose level of knowledge you don't know.

Tiffany: I might want to follow top physios...

Oscar: I only write something if I genuinely feel that I've got a valid argument about it because you wouldn't want a wishy-washy argument. So, it's important who tweets, you want to learn from crème de la crème.

Students were 'bothered' by the issue of credibility and status, they positioned themselves as "incompetent" against the APT in this Twittosphere (=the Twitter platform) (Rinaldo et al., 2011). Such "subordinate" positioning evokes the concern about how hierarchical status and power are reproduced in the society, education yet being another place of that struggle (Apple, 2013). Indeed, HE is just one more stage of tutor-student power positioning, where issues of "resistance and power" surface even in initiatives that aim to "empower" students and give them "voice" (Seale, Gibson, Haynes, \& Potter, 2015). The 
resistance that Seale et al. (2015) talk about is the same kind of resistance noted in this study: students' resistance to actively participate in spite of the "planned" learning benefits. It may be that the tutor-researcher's large pool of followers and their contributions to the hashtag outside the student group discouraged students to participate rather than provided more opportunities for reaching and engaging with practitioners and experts around the world, as it was envisaged. What this study authors thought was a unique opportunity to engage with international experts via the module hashtag, the students may have experienced as overwhelming and intrusive, which may have added even more to their feeling of subordination. Furthermore, Seale et al. (2015, p. 547) link this power issue to the lack of "ownership" and "expertise" from the students' side. Indeed, ownership is hard to achieve if students perceive Twitter as a space for experts that they do not belong to. First year students are experiencing a big educational transition into the world of Higher Education where they are positioned at the periphery of disciplinary and practical expertise, which may be yet another reason why they chose not to engage. The results may be indeed different if the students were in their final year of university. As signaled by Knight and Kaye (2014), when it comes to HE, Twitter might be more suitable for academics and final year students. In terms of academic staff, it can mean academic professional power that enhances individual research profile and visibility. Academics are under pressure to increase the public "impact" of their research and it is steadily becoming clear that Twitter can help (Knight \& Kaye, 2014). With an increase of such “APT” people dominating Twitter, Year1 students may remain passive Twitter observers, unless they become "owners" of learning initiatives, as it will be presented in the following section.

\subsection{Enablers: what may help students use Twitter for learning}


In relation to what would encourage novice students to use Twitter for learning, a list of the most prominently mentioned factors was identified. The strong feeling among students was that they needed a tutor's help to create a 'Twitter learning habit'. Students talked about the need for tutor ongoing instruction and thus answered our question as to whether Year1 students desired tutor intervention when it comes to SM use for learning: yes, they did. The need for tutor's instructional support in modelling the activity has been confirmed here, in line with Ross, Banow and Yu (2015). Yet, one of the central themes for enabling student contribution was around student "ownership", just as Seale et al. (2015, p. 547) reflect. These are the "enablers" that students identified:

\section{STUDENT OWNERSHIP}

- $\quad$ Students create a Twitter hashtag/profile, manage and develop it themselves; the tutor adds personal and networked expertise later in the process

- $\quad$ Students lead and manage peer-to-peer engagement, having designated hashtag or profile "moderators"

\section{TUTOR INSTRUCTIONAL LEAD}

- Encourage \# or profile content that is relevant to students' levels of understanding and prior knowledge

- Discuss course papers with a twist: i.e. tweet a related challenge

- $\quad$ Provide clear and regular in-classroom encouragement and announcements: e.g. announcing post-session tweeting at the end of each session

- $\quad$ Provide examples of more 'learning-friendly' types of tweet. What is meant by this is for example explaining the difference between 1) a tweet that expresses some critical commentary in 140 characters and a 2) re-tweet of a link to a resource 
- $\quad$ Suggest interesting and relevant profiles to 'follow'; invite students to identify some themselves and discuss it

- Use Twitter as an embedded lecture method - Twitter streams/tweets/profiles are streamed and referred to by the lecturer during a lecture

The suggestions here relate to and add to other existing principles of what works with Twitter and social media (e.g. Chickering \& Ehrmann, 1996), cautious of any attempts to make an "one size fits all" list. Applications and effects of the reported suggestions will depend on many contextual factors, such as subject-discipline, students' year of study, institutional and micro-culture. Furthermore, there may be obstructing factors such as standardised practice requirements as in our case and/or limited lecturer's time. All the enablers above are student-perceived triggers for engagement and they do not mean learning. Whether they can be pursued or not depends on the micro-level of student-tutor relationship, subject field culture and practice, individual beliefs, the meso-level of departmental pedagogical culture and policy as well as the macro-level of institutional and government policy. If we add to this that the use of SM by young people is "complex, convoluted and contradictory" (Selwyn \& Stirling (2016) quoting Boyd, 2014, p.4), neat suggestions on what works in learning with SM become complicated. What we stress here is that tweet information needs to be critically activated in order to lead to learning. This is discussed in the next section.

\section{Implications for the use of Twitter (and SM) in HE learning:}

\section{Digital Information Activation (Dig-Info-Act) towards action and change}


Dealing with the obstacles and enablers above is not where this learning story ends, it is where it begins. An approach, that is here termed "Digital Information Activation" (DigInfo-Act) Pedagogy, is introduced to challenge the perceived dominant business and power role of Twitter and SM. This approach stresses the need to "own and act upon" any online information so that it could be transformed into learning. The "acting" in question needs to be framed within a critical attitude and an orientation not only towards action upon information in the learning context, but also towards a possibility for action in real life. The approach is sketched and described in this section as an initial attempt, needing further development and conceptualisation.

Why is the word "activation" used? In many cases the information on SM including Twitter is simply not "activated" to be transformed into learning. What the claimed SM contribution to students' learning might actually be resembles more the use of SM in the form of 'updates', 'trends in the field', electronic "word of mouth" (Jansen, Zhang, Sobel, \& Chowdury, 2009), 'providing and sharing information' in a "talk” form. Karlin (2007, p.7) claims that nearly ' $60 \%$ of high school students who use social networking talk about education online, and more than $50 \%$ talk about specific school work noted and information location'. Such student “talk" might serve to 'lubricate' the sense of belonging to a group of learners and lead to learning. Yet, the question is if such talk counts as learning. It depends on how learning with SM is defined.

Just accessing information on Twitter (on SM and online) might not lead to any significant learning or transformative effect. In terms of academic development (e.g. at a basic level evident in formative, summative or any other type of assessment), this development can be activated if the student acts upon information (=tweet) in some way, supported by the tutor, via an expressive mode. Just scrolling down and passing on 
information can be a kind of learning experience, but its depth is questionable. This concern with "using" something in a manner of information passing reflects Shepherd's (2010) worry that "we're all becoming very good at passing interesting information on from one to another, but not actually reading and reflecting on any of it." It has been noted that people increasingly re-tweet comments with links without looking into the link content (Carrigan, 2015). This signals "social media fatigue" (Shepard, 2010). What matters in SM for learning is what happens with this "access" possibility, how tutors and students do "information activation" to lead towards learning and hopefully learning for critical and informed action. Indeed, learning manifests itself beyond the grade via students' socio-cultural and community presence, relations and identity; it entails creative practices, socially just engagement with the world, curriculum, future prospects, visions and an open horizon of possibilities and capabilities.

Digital Information Activation Pedagogy requires discussing with students about what online (here tweet) contribution means in practical, learning and critical terms and where it can lead to, but it cannot be too rigid or prescriptive either. Twitter hashtag (\#) search can provide different information sources and experiences from a wide range of users which represents different information contextualisation. In that respect, students' understanding is enriched once they engage with a couple of different contextual contents (expressed in tweets) on the same topic/concept (searched by hash tag \#). This is in line with Ross's (2011) idea on concept learning as an understanding of the contextual variations and particularities where a concept is realised. Such contextual exploration can be a starting point for critical digital information activation pedagogy. Critical "Dig-InfoAct" pedagogy combines critical media literacy (Kellner \& Share, 2007) and the idea of students as active producers of content, research and artefacts (Neary \& Winn, 2009) in relation to teaching-learning practices. It intends to support students to "dig out" relevant 
digital information, explore and evaluate that information critically, and finally "act" to activate the found information via creative and productive practices. This acting evokes Chickering and Ehrmann's (1996, p.3) “active learning techniques”, as they argue that "Learning is not a spectator sport", but means talking, writing reflectively, relating to past experiences, applying in daily lives. To expand on it, student creative practice could involve creating an "outlet" for the reflection on information and further exploration, such as reflecting on a tweet thread in a blog commentary, via a video, an illustration, in a formal assignment or any other student-preferred medium or artefact of expression.

To open possibilities for critical pedagogy and challenge students' positioning of "subordinates" of Twitter, a tutor can encourage student joint ownership of hashtags or profiles and discussions on the social effect of a Twitter thread or news in relation to knowledge, power, race, region, nationality, equality, community and society needs and actions. This critical pedagogy with Twitter resembles the idea of "technoliteracy from below", that is, a pedagogical initiative to look out for and legitimise "counter-hegemonic needs, values and understanding (...) as opposed to the largely functional, economistic, and technocratic technoliteracy "from above" that is favoured by many industries and states (Suoranta \& Vadén, 2007, p.159, quoting Kellner \& Kahn (2006)”. However, if it persists at the individual rather than collective organisational level, this pedagogy will not turn into culture that leads to noticeable learning or social change.

Above all, students need to feel free not to engage with Twitter for learning or any other purposes. Whatever they decide, there will be some sort of exclusion though: by participating and contributing, they will exclude the ones who do not want to and/or cannot do so; on the other hand, the non-contributors are excluded from a possibly potent well of information and learning opportunities. 


\section{Conclusion}

This article provides some insights on how a group of Year 1 undergraduate physiotherapy students perceive Twitter and its role in their learning. Findings show that few students use Twitter for social purposes and a vast majority never use it for perceived 'learning' purposes. In addition, mobile devices are rarely used for academic study. With regard to the module hashtag created for their course, the students chose not to contribute to it. The dominant student reflection on the reasons behind this outcome was the distinction of 'Twitter' as an artefact for the celebrity-like knowledgeable and intimidating Twitter users (Academic and Professional Twitterati (APT)) as well as an artefact for developing career which they can focus on later. Such perception demarcated students as less knowledgeable, powerful and capable, the "subordinate" positioning which is here problematised. It is argued that it would be beneficial if students were informed on various possible uses of SM and Twitter, either as a part of their SM training or within courses, such as examining Twitter discourse and information critically and using Twitter in relation to social justice and activism. With regard to formal learning, Year 1 students wanted a tutor's help to create the tweeting habit and to provide examples of what counts as learning with Twitter. They also shared insights on the "Twitter for learning" enablers that are here proposed to be embedded within a critical "digital information activation" (Dig-Info-Act) pedagogy with Twitter in HE, an approach introduced here by the authors. Further studies, nationally and internationally, are needed to explore, develop, conceptualise, confirm or critique the perspectives germinated here, especially when it comes to different disciplines and student year of studying, "APT", student "subordination" and "Dig-Info-Act" pedagogy approach. 


\section{References}

Ashwin, P., \& McVitty, D. (2015). The Meanings of Student Engagement: Implications for Policies and Practices. In A. Curaj, L. Matei, R. Pricopie, J. Salmi, \& P. Scott (Eds.), The European Higher Education Area (pp. 343-359). Springer International Publishing.

Apple, M. W. (2013). Education and Power. New York: Routledge.

Bennett, W. L. (2012). The Personalization of Politics, Political Identity, Social Media, and Changing Patterns of Participation. The ANNALS of the American Academy of Political and Social Science, 644(1), 20-39.

Blessing, S. B., Blessing, J. S., \& Fleck, B. K. B. (2012). Using Twitter to Reinforce Classroom Concepts. Teaching of Psychology, 39(4), 268-271.

Bulearca, M., \& Bulearca, S. (2010). Twitter: a viable marketing tool for SMEs. Global Business and Management Research: An International Journal, 2(4), 296-309.

Carrigan, M. (2015). Surviving life in the accelerated academy: prospects and problems for digital scholarship, SRHE event "Academic identity in the digital university: current trends and future challenges", September 2015, SRHE, London. Unpublished Resource (presentation).

Chickering, A. W., \& Ehrmann, S. C. (1996). Implementing the seven principles: Technology as lever. AAHE bulletin, 49, 3-6.

Comm, J. (2010). Twitter Power 2.0: How to Dominate Your Market One Tweet at a Time. John Wiley \& Sons.

Earl, J., McKee Hurwitz, H., Mejia Mesinas, A., Tolan, M., \& Arlotti, A. (2013). This Protest Will Be Tweeted. Information, Communication \& Society, 16(4), 459-478.

Ebner, M., Lienhardt, C., Rohs, M., \& Meyer, I. (2010). Microblogs in Higher Education-A chance to facilitate informal and process-oriented learning? Computers \& Education, 55(1), 92-100. 
Ellison, N. B., Steinfield, C., \& Lampe, C. (2011). Connection Strategies: Social Capital Implications of Facebook-enabled Communication Practices. New Media \& Society, $\mathrm{XX}(\mathrm{X}), 1-20$.

Evans, C. (2013). Twitter for teaching: Can social media be used to enhance the process of learning? British Journal of Educational Technology, n/a-n/a.

Forkosh-Baruch, A., \& Hershkovitz, A. (2012). A case study of Israeli higher-education institutes sharing scholarly information with the community via social networks. The Internet and Higher Education, 15(1), 58-68.

Fox, B. I., \& Varadarajan, R. (2011). Use of Twitter to encourage interaction in a multi-campus Pharmacy Management course. American Journal of Pharmaceutical Education, 75(5), 1-9.

Gikas, J., \& Grant, M. M. (2013). Mobile computing devices in higher education: Student perspectives on learning with cellphones, smartphones \& social media. The Internet and Higher Education, 19, 18-26.

Giroux, H. A. (1988). Teachers as intellectuals: Toward a critical pedagogy of learning. Greenwood Publishing Group.

Greenhow, C., \& Lewin, C. (2016). Social media and education: reconceptualizing the boundaries of formal and informal learning. Learning, Media and Technology, 41(1), 6-30.

Gottfried, J. \& Shearer, E. (2016). News Use Across Social Media Platforms 2016. Pew Research Center. Retrieved from: http://assets.pewresearch.org/wpcontent/uploads/sites/13/2016/05/PJ_2016.05.26_social-media-and-news_FINAL-1.pdf

Hands, J. (2011). @ Is For Activism: Dissent, Resistance And Rebellion In A Digital Culture. Pluto Press.

Henderson, M., Selwyn, N., Finger, G., \& Aston, R. (2015). Students' everyday engagement with digital technology in university: exploring patterns of use and 'usefulness'. Journal of Higher Education Policy and Management, 37(3), 308-319. 
Jacquemin, S. J., Smelser, L. K., \& Bernot, M. J. (2014). Twitter in the Higher Education

Classroom: A Student and Faculty Assessment of Use and Perception. Journal of College Science Teaching, 43(6), 22-27.

Jansen, B. J., Zhang, M., Sobel, K., \& Chowdury, A. (2009). Twitter power: Tweets as electronic word of mouth. Journal of the American Society for Information Science and Technology, 60(11), 2169-2188.

Junco, R., Heiberger, G., \& Loken, E. (2011). The effect of Twitter on college student engagement and grades. Journal of Computer Assisted Learning, 27(2), 119-132.

Kanjanapongpaisal, P., Rogers, S., \& Bryan, W. (2012). Twitter Usage in Higher Education. In World Conference on Educational Multimedia, Hypermedia and Telecommunications (Vol. 2012, pp. 2145-2150).

Kellner, D., \& Share, J. (2007). Critical media literacy is not an option. Learning Inquiry, 1(1), 5969.

Karlin, S. (2007). Examining how youths interact online. School Board News, 73(4), 6-9.

Knight, C. G., \& Kaye, L. K. (2014). 'To tweet or not to tweet?'A comparison of academics' and students' usage of Twitter in academic contexts. Innovations in Education and Teaching International, (ahead-of-print), 1-11.

Knowlton, D. S., \& Nygard, S. (2016). Twitter in the Higher Education Classroom: Known Fragmentations and Needed Frameworks. Journal on Excellence in College Teaching, 27(1), $117-151$.

Loudon, L., \& Hall, H. (2010). From triviality to business tool: The case of Twitter in library and information services delivery. Business Information Review, 27(4), 236-241.

Molesworth, M., Nixon, E., \& Scullion, R. (2009). Having, being and higher education: The marketisation of the university and the transformation of the student into consumer. Teaching in Higher Education, 14(3), 277-287. 
Neary, M., \& Winn, J. (2009). Student as producer: Reinventing the undergraduate curriculum. The future of higher education: Policy, pedagogy and the student experience, 192-210. Rinaldo, S. B., Tapp, S., \& Laverie, D. A. (2011). Learning by Tweeting: Using Twitter as a Pedagogical Tool. Journal of Marketing Education, 33(2), 193-203.

Roblyer, M. D., McDaniel, M., Webb, M., Herman, J., \& Witty, J. V. (2010). Findings on Facebook in higher education: A comparison of college faculty and student uses and perceptions of social networking sites. The Internet and Higher Education, 13(3), 134-140. Ross, J. (2011). Unmasking online reflective practices in higher education. Unpublished Ph. D thesis. University of Edinburgh.

Ross, H. M., Banow, R., \& Yu, S. (2015). The Use of Twitter in Large Lecture Courses: Do the Students See a Benefit? Contemporary Educational Technology, 6(2), 126-139.

Schneider, F., \& Goto-Jones, C. (2014). Revisiting the Emancipatory Potential of Digital Media in Asia-Introduction to the Inaugural Issue of Asiascape: Digital Asia. Asiascape: Digital Asia, $1(1-2), 3-13$.

Shepherd, C., (2010), "1000 tweets but still not sure why”, Clive on Learning, 5 January. Retrieved from: http://clive-shepherd.blogspot.fr/2010/01/1000-tweets-but-still-not-surewhy.html

Seale, J., Gibson, S., Haynes, J., \& Potter, A. (2015). Power and resistance: Reflections on the rhetoric and reality of using participatory methods to promote student voice and engagement in higher education. Journal of Further and Higher Education, 39(4), 534-552.

Selwyn, N., \& Stirling, E. (2016). Social media and education... now the dust has settled. Learning, Media and Technology, 41(1), 1-5.

Speight, S., Lackovic, N., \& Cooker, L. (2013). The Contested Curriculum: Academic learning and employability in higher education. Tertiary Education and Management, 19(2), 112-126. Statista (2016). Social Media statistics and facts. May 2016. Retrieved 
from: https://www.statista.com/topics/1164/social-networks/

Suoranta, J. \& Vadén, T. (2007). From social to socialist media: The Critical potential of the wiki world. In Peter Mc Laren and Joe L. Kincheloe (Eds) Critical pedagogy: Where are we now? (pp.143-163). New York: Peter Lang.

Vaismoradi, M., Turunen, H., \& Bondas, T. (2013). Content analysis and thematic analysis: Implications for conducting a qualitative descriptive study. Nursing \& Health Sciences, 15(3), 398-405.

Welch, B. K., \& Bonnan-White, J. (2012). Twittering to increase student engagement in the university classroom. Knowledge Management \& E-Learning: An International Journal (KM\&EL), 4(3), 325-345. 

